\title{
[74] Proteinase Inhibitors from Boar Seminal Plasma
}

\section{By Hans Fritz, Harald Tschesche, and Edwin Fink}

During investigations on the distribution and possible function of proteinase inhibitors in various animals, Haendle et al. found high antitryptic activity in seminal vesicles and seminal plasma of various species including the boar.1. The antiproteolytic activity derived from acidstable, low-molecular-weight proteins. These were also found in lower concentrations in extracts of boar testes and epididymis. ${ }^{2}$ Later, a mixture of related inhibitory active glycoprotcins was isolated by Fink et al. employing affinity chromatography on water-insoluble trypsin-resin. These were characterized by the average molecular weights, estimatod by gel filtration; and some molecular properties and their strong inhibition. of bovine trypsin and porcine plasmin. ${ }^{3}$ Independently, Zaneveld at al: purified also an acid-stable, low-molccular-wcight trypsin inhibitor from boar seminal plasma and calculated its molecular weight as 67.81 on the basis of the amino acid composition. ${ }^{4}$ The purification of the inhibitors from baar seminal plasma and spermatozoa to homogeneity was reported by Tschesche et al.5. The boar seminal inhibitors described by Polakoski et al. ${ }^{6}$ are most probably identical with the inhibitors presented in this chapter (cf. the discussion on this subject by Fritz ot al. ${ }^{7}$ and Tschesche and Kupfer ${ }^{8}$ ).

Trypsin inhibitors from boar seminal plasma and spermatozoa are strong inhibitors of boar and human acrosins., ${ }^{0,10}$ This inhibitory speci-

'H. Haendle, H. Fritz, I. Trautschold, and E. Werle, Hoppe Seylery Z. Physiol. Chem. 343, 185 (1965).

${ }^{2}$ H. Haendle; Dissertation (M.D. Thesis), Medienl Faculty of the University of Munich, 1969.

'E. Fink, G. Klcin, F. Hammer, G. Müller-Bardorff, and H. Fritz; Proleinase Inhibitors, Proc. Int. Res. Conf., 1st, Munich, 1970, p. 225.

'L. J. D. Zaneveld, K. L. Porakoski, R. I. Rohertson, and W. L. Wiltiams, Proteinase Inhibitors, Proc. Int. Res. Conf., 1st, p. 236.

- H. Tschiesche; \$. Kuppfer, O. Eongel, R. Klanser, M. Meier, and H. Fritz, Proleinase Inhibilows, Proc. Int. Res. Confi, and (Bayer Symp. V), Grosse Ledder, 1979.

'K. L. Pokakoski and W, ho Williams, Proteinase Inhibitors, Proc. Int. Res. Conf,, Ind (Bayer Symp. V), Grosse Ledder, 1979, p. 156.

'H. Fritz, H. Schiessler, W.-B. Schill, H. Tschesehe, N. Heimbunger, and O. Wallner, in "Proteaseg and Biologieal Control" (E. Reieb, D. Rifkin, ant E. Staw, eds.) p. 737. Cold Spring Harbor Laboratory, Cold Spring Harber, New York, 1975.

${ }^{3} \mathrm{H}$. Tsehesche and S. Kupfer, unperblished results, 1975.

- H. Pritz, B. Förg-Brey, E. Fink, H. Sehiessler, E. Jaumann, and M. Arnhold, Hoppe-Seyler's Z. Physiol. Chem. 353, 1007 (1972).

${ }^{10} \mathrm{H}$. Pritz, B. Förg-Brey, M. Meicr, M. Arnhold, and H. Techesche, Hoppe-Seuler's Z. Physiol. Chem. 353, 1950 (1972). 
ficity, the unusual glycoprotein nature and the unexpected homology between the pancreatic secretory trypsin inhibitors (Kazal type) and the boar seminal acrosin inhibitors reported recently by Tschesche et al. ${ }^{11}$ make these inhibitors an interesting subject for studies in the areas of fertilization, structure-function relationships, and inhibitor evolution. ${ }^{7,8}$

\section{Assay Methods}

Principles. The substrate $N^{\alpha}$-benzoyl-DL-arginine $p$-nitroanilide (BAPA) was used for measuring proteolytic activity and the inhibition of bovine trypsin, ${ }^{12-14}$ porcine plasmin, ${ }^{12,15}$ and boar and human acrosin ${ }^{9,10,14}$ by the change in absorbance at $405 \mathrm{~nm}$.

Known methods were employed to assay the inhibition of bovine chymotrypsin, ${ }^{12,14}$ porcine pancreatic kallikrein, ${ }^{12}$ bovine thrombin, ${ }^{16}$ and human neutral leukocytic proteinases. ${ }^{14}$

Definition of Unit and Specific Activity. One enzyme unit corresponds to the hydrolysis of $1 \mu$ mole of substrate (BAPA) per minute $\left(\Delta A_{405} / \mathrm{min} \mathrm{cm}=3.32\right.$ for $\left.3 \mathrm{ml}\right)$. One inhibitor unit reduces the activity of two enzyme units by $50 \%$, thus decreasing the absorbance by $3.32 /$ minute and $\mathrm{cm}$ for $3 \mathrm{ml}$. The specific activity corresponds to inhibitor units (BAPA) per milligram of protein. ${ }^{12,13}$

\section{Purification Procedure}

Different procedures may be used to isolate proteinase inhibitors from seminal plasma and spermatozoa, depending on the starting material and the desired objectives, e.g., isolation on a large scale or in high yield and of material with high specific activity or of apparent homogeneity with respect to the protein moiety. Seminal plasma contains various glycosidases and proteinases ${ }^{17}$ suspected of causing degradation of the inhibitors starting immediately after ejaculation. As long as effective inactivation of these enzymes cannot be achieved, acidification of the

"H. Tschesche, S. Kupfer, R. Klauser, E. Fink, and H. Fritz, in "Protides of the Biological Fluids, 23rd Colloquium" (H. Peeters, ed.), p. 255. Pergamon, Oxford and New York, 1976.

${ }^{12} \mathrm{H}$. Fritz, I. Trautschold, and E Werle, in "Methoden der enzymatischen Analyse" (H. U. Bergmeyer, ed.), p. 1103. Verlag Chemie, Weinheim, 1974.

${ }^{12} \mathrm{~B}$. Kassell, this series Vol. 19, p 844.

${ }^{14} \mathrm{H}$. Schiessler, E. Fink, and H. Fritz, this volume [75].

${ }^{13}$ E. Fink and H. Fritz, this volume [73].

"The kallikrein estimation procedure was used."

"L. J. D. Zaneveld, K. L. Polakoski, and G. F. B. Schumacher, in "Proteases and Biological Control" (E. Reich, D. Rifkin, and E. Shaw, eds.) p. 683. Cold Spring Harbor Laboratory, Cold Spring Harbor, New York, 1975. 
seminal plasma is the method of choice in order to prevent hydrolytic degradation. Cleavage of carbohydrate residues, e.g., of sialic acids and fucose, and hydrolysis of acid-labile peptide (Asp-Pro bonds ${ }^{11}$ ) and carboxamide bonds, is an inevitable disadvantage. Nevertheless, sufficient amounts of active, and in the protcin backbone unaffected, inhibitors have been obtained under the conditions described below, using deproteinization of the seminal plasma in $3 \%$ perchloric acid or acidification to $\mathrm{pH} 1-2$, followed by affinity chromatography on CM-cellulose trypsin.

Step 1. Collection of Seminal Plasma and Spermatozoa. Boar semen is collected using an artificial vagina, filtered through gauze, and centrifuged at $600 \mathrm{~g}$ for $10 \mathrm{~min}$. The supernatant is centrifuged for $30 \mathrm{~min}$ at $1000 \mathrm{~g}$ and $4^{\circ}$, and treated according to step 2 or stored at $-40^{\circ}$. The sperm pellet is twice resuspended in saline and centrifuged in order to remove unspecifically adsorbed substances. The pellet is then processed according to step 2 (Section II) or frozen at $-196^{\circ}$ and stored at $-40^{\circ} . .^{8}$

\section{Purification of Seminal Plasma Inhibitors}

Step 2. Acid Deproteinization. A prepurification of the inhibitors and denaturation of the seminal plasma enzymes is possible by one of the following procedures.

METHOD 1: REPROTEINization. The seminal plasma is mixed with an equal volume of $6 \%(\mathrm{w} / \mathrm{v})$ perchloric acid (see method $\mathrm{I}$, step $\mathbf{1}^{15}$ ). The clear inhibitor solution thus obtained may be directly applied to affinity chromatography on a trypsin resin (step 3) after neutralization ( $\mathrm{pH} 7.8$ ) and addition of solid scdium chloride to a final concentration of about $0.4 M$.

Method 2: acidification. Seminal plasma is adjusted to $\mathrm{pH} 1$ by addition of $3 \%(\mathrm{w} / \mathrm{v})$ perchloric acid or $2 \mathrm{~N} \mathrm{HCl}$, which inactivates the enzymes and increases the yield of free inhibitor by dissociation of the acrosin-inhibitor complex. The acidified solution is stored for $15 \mathrm{hr}$ at $4^{\circ}$ and then centrifuged ( $30 \mathrm{~min}, 1200 \mathrm{~g}$ ). The supernatant inhibitor solution is readjusted to $\mathrm{pH} 7.8$ by addition of triethanolamine and made up to a final concentration of $0.4 M$ sodium chloride.

Step 2 may be omitted and trypsin resin be directly applied in a batch operation to the native seminal plasma at $4^{\circ}$.

Step 3. Affinity Chromatography. Deproteinized inhibitor solutions of low viscosity may be applied to any water-insoluble trypsin derivative available. A suitable flow rate in the affinity column is essential. Native seminal plasma or turbid inhibitor solutions are best applied to such

${ }^{18}$ W.-D. Schleuning and H. Fritz, this volume [27]. 
trypsin derivatives, which can be easily removed by centrifugation. Trypsin cellulose (bovine trypsin bound to CM-cellulose, 7-10 U/mg, E. Merck, Darmstadt, West Germany) is especially suitable. Working temperature is $4^{\circ}$ throughout. Details of the procedure are described in this volume ${ }^{14,15,19}$ and by Fritz et al. ${ }^{\text {? }}$

The affinity adsorbent ( $10 \mathrm{~g})$ is preconditioned by suspending it repeatedly in $0.4 M \mathrm{NaCl}, 0.1 M$ triethanolamine- $\mathrm{HCl}, \mathrm{pH} 7.8$, and in $1.0 M \mathrm{KCl}-\mathrm{HCl}, \mathrm{pH} \mathrm{2.0,} \mathrm{until} \mathrm{the} \mathrm{supernatant} \mathrm{is} \mathrm{free} \mathrm{of} \mathrm{tryptic} \mathrm{activity.}$ After reequilibration in $\mathrm{pH} 7.8$ buffer, the trypsin cellulose is added to native scminal plasma or the inhibitor solution from step 2 and gently stirred or shaken for $30-60 \mathrm{~min}$. About $100 \mathrm{ml}$ of wet trypsin cellulose is recommended per liter of seminal plasma containing 700-1000 IU (trypsin inhibition). Subsequently, the suspension is centrifuged (1000 g, $5 \mathrm{~min}$ ) and the inhibitor-loaded resin (precipitate) is washed five times with the pH 7.8 buffer and once with a $1: 10$ dilution of the same buffer.

The inhibitors are dissociated from trypsin at acid $\mathrm{pH}$. The adsorbent (100 ml wet volume) is suspended four to five times in $300 \mathrm{ml}$ of $0.4 \mathrm{M}$ $\mathrm{KCl}-\mathrm{HCl}, \mathrm{pH} \mathrm{2.0}$, and then filtered or centrifuged. The first extract containing only low amounts of inhibitors is discarded. The $\mathrm{pH}$ of the second suspension has to be readjusted to 2.0 with $2 \mathrm{~N} \mathrm{HCl}$. The major portion of inhibitors is found in the second extract.

The acidic extracts are combined, neutralized, and desalted by repeated ultrafiltration using the Diaflo membranés" UM-05 or UM-2. After lyophilization, inhibitor preparations with specific activities of 1.9$2.2 \mathrm{IU} / \mathrm{mg}$ are obtained. The yields depend on the quality of the starting material: If deproteinized inhibitor solutions are applied, between 82 and 93\% of the inhibitors bound to the trypsin cellulose are recovered. Native seminal plasma contains besides the acid-stable inhibitors, also highmolecular-weight (above 45,000), acid-labile inhibitors, probably of plasmatic origin. These inhibitors are also bound-at least partially-to the resin; however, they are denatured during the acidic extraction at $\mathrm{pH}$ 2.0. Depending on the varying amounts of these inhibitors in native seminal plasma, between 74 and $90 \%$ of the inhibitory activity bound to the affinity adsorbent is thus recovered in the acidic extracts. The purity of this inhibitor preparation is $70-80 \%$. However, the inhibitor material is heterogeneous and, besides the homologous isoinhibitors $A, A_{1}$, and (or) $\mathrm{B}$, contains at least 15-20 multiple chromatographic forms due to microheterogeneity in the carbohydrates.

Step 3a. Gel Filtration. The mixture of inhibitors obtained in step 3 is separated into two major fractions by gel filtration on Sephadex G-75

${ }^{2} \mathrm{H}$. Tschesche, this volume [69]. 
either in slightly alkaline (pH 7.6) or acidic (pH 2.6) salt-buffer solutions. The main portion of the inhibitors is cluted in the molecular weight range $5500-6800$ and 10,500-12,800 (pH 7.6) or cven higher. In a typical experiment, $3 \mathrm{ml}$ of the inhibitor solution containing $13 \mathrm{IU}$ are applied to a $1.6 \times 122 \mathrm{~cm}$ column of Sephadex G-75 equilibrated and developecl with $0.4 M \mathrm{NaCl}, 0.1 M$ tricthanolaminc- $\mathrm{HCl}, \mathrm{pH} \mathrm{7.6}$, at a flow rate of $12 \mathrm{ml} / \mathrm{hr}$; fractions of $4 \mathrm{ml}$ are collected." The two major inhibitor fractions eluted in the molccular weight range mentioned above were desalted by repeated ultrafiltration and lyophilized (cf. step 3 ). The material used for immunization experiments was subjected to a second gel filtration under the same conditions. The fractions were designated BSTI-II (MV about 6000 ) or BSTI-I (MW about 12,000 ), respectively.

Native seminal plasma when fractionated by gel filtration under the same conditions separates into three major acrosin-trypsin inhibitor fractions, a high-molecular-weight, acid-labile one, and the acid-stable inhibitor fractions I and II. ${ }^{i, 20}$ Both inhibitor fractions $I$ and II can be purified independently by affinity chromatography as described in step 3 . Inhibitor preparations with specific activities of $2.0 \mathrm{IU} / \mathrm{mg}$ for BSTI-I and $2.8 \mathrm{IU} / \mathrm{mg}$ for BSTI-II are thus obtained. The difference between the inhibitor fractions I and II scems to refer only to the carbohydrate portions. The same general fractionation patterns have been obtained applying inhibitor material from step 3 and from the fraction II (step 3a) to chromatography on SE-Scphadex (step 4). Both preparations, from step 3 and fractions I or II from step $3 a$, seem to be equally well suited for further fractionation.

Step 4. Chromatography on SE-Sephadex." SE-Scphadex C-25 is equilibrated with $0.025 M$ ammonium acctate, $\mathrm{pH} 6.8$, transferred to a chromatography column, $4.5 \times 40 \mathrm{~cm}$, which is equilibrated with the $0.025 M$ buffer until the $\mathrm{pH}$ of the effluent is 6.8 . Inhibitor, $200 \mathrm{mg}$ (1.95 $\mathrm{IU} / \mathrm{mg}$ ) is dissolved in the cquilibration buffer and applicd to the column. Elution is carried out with a four-step ammonium acetate gradient of increasing molarity at $\mathrm{pH} 6.8$ and room tempcrature. The gradient is prepared by mixing buffers of the following concentrations: $0.05 M$ to $0.025 M(100 \mathrm{ml})$ until tube $200(\mathrm{a}), 0.15 M$ to $0.05 M(200 \mathrm{ml})$ until tube 400 (b), $0.75 M$ to $0.15 M(200 \mathrm{ml})$ until tube 600 (c). Finally, $0.75 M$ buffer is applied to the column ( $d$ and e in Fig. 1). The flow rate is adjusted to $40 \mathrm{ml} / \mathrm{hr}$ and $4-\mathrm{ml}$ fractions are collected. The column effluent is monitored by its absorption at $280 \mathrm{~nm}$ and by its trypsininhibiting activity. The active material is distributed among four major peaks (I, II, III, IV in Fig. 1) and several smaller ones. The elution ${ }^{20}$ H. Fritz, W.-D. Schleuning, and W.-B. Schill, Proteinase Inhibitors, Proc. Int. Res. Conf., 2nd (Bayer Symp. V), Grosse Ledder, 1979, p. 118. 


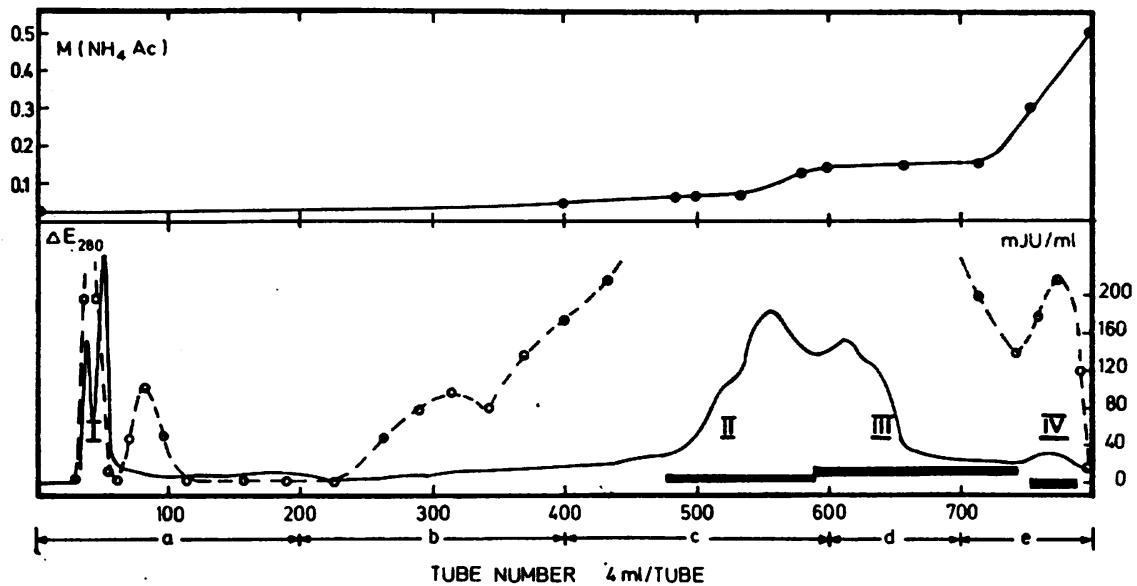

Fig. 1. Gradient clution chromatography of crude boar seminal plasma inhibitor on SE-Sephadex C-25. For experimental conditions, see step I, 4. Top: ammonium acetate gradient molarity. Bottom: - absorbance at $280 \mathrm{~nm} ; 0--\mathrm{O}$, trypsin inhibition.

pattern varies considerably with inhibitor materials derived from seminal plasma of different animals and is strongly dependent on the age and pretreatment of the seminal plasma. Each peak is pooled separately as indicated by the bars. The pools are concentratcid by rotary evaporation, desalted by gel filtration on Bio-Gel P-2 columns, $1.5 \times 80 \mathrm{~cm}$, equilibrated with $0.1 M$ acetic acid, and lyophilized.

Peak I contains the most acidic inhibitor which still contains one residue of sialic acid per molecule. ${ }^{21}$ The preparation is contaminated with some of the inactive material which is mainly eluted in the subsequent fraction containing the cleaved acidic and neutral sugars (sialic acid, fucose, mannose, galactose, galactosamine, glucose, and glucosamine). The specific activity of this inhibitor is about $1 \mathrm{IU} / \mathrm{mg}$ after rechromatography under the same conditions. The main portion of the inhibitory activity is recovered in fractions II and III. The preparations obtained from these fractions are devoid of sialic acid. The specific activity of peak II is about $2.3 \mathrm{IU}$, and of peak III about $2.8 \mathrm{IU} / \mathrm{mg}$. Peak IV was present in some, but not all, batches of seminal plasma inhibitors investigated. Its specific activity is about $2.8 \mathrm{IU} / \mathrm{mg}$. Isoinhibitor $\mathrm{B}(67$ amino acid residues; see Table I) was isolated from this peak after rechromatography.

Amino acid analysis and cellulose acetate electrophoresis at $\mathrm{pH} 7.8$ reveal that none of the fractions is homogeneous. However, preparations

${ }^{21}$ G. Decker, Diplomarbeit, Technical University of Munich, 1974. 
TABLE I

Amino Acid Composition of Skminal Acrosin Inhibitorsa

\begin{tabular}{|c|c|c|c|c|}
\hline \multirow[b]{2}{*}{ Amino acid } & \multicolumn{3}{|c|}{ Boar isoinhibitors from plasma } & \multirow{2}{*}{$\begin{array}{c}\text { Boar } \\
\text { upormalaz: }\end{array}$} \\
\hline & A & $\mathbf{A}_{\mathbf{1}}$ & B & \\
\hline Aspartic acid & 7 & 7 & 7 & 7 \\
\hline Threonine & 4 & 4 & 4 & 4 \\
\hline Serine & 5 & 5 & 5 & 5 \\
\hline Glutamic acid & 5 & 5 & 5 & 5 \\
\hline Proline · & 3 & 3 & 3 & 3 \\
\hline Glycine & 5 & 5 & 5 & 5 \\
\hline Alanine & 2 & 2 & 2 & 2 \\
\hline Valine & 1 & 1 & 1 & 1 \\
\hline IIalf-cystine & 6 & 6 & 6 & 6 \\
\hline Methionine & 1 & 1 & 1 & 1 \\
\hline Isoleucine & 2 & 2 & 2 & 2 \\
\hline Leucine & 2 & 2 & 2 & 2 \\
\hline Tyrosine & 3 & 3 & 3 & 3 \\
\hline Phenylalanine & 5 & 5 & 5 & 5 \\
\hline Lysine & 5 & 4 & 6 & 4 \\
\hline Histidine & 3 & 3 & 3 & 3 \\
\hline Arginine & 5 & 6 & 6 & 5 \\
\hline \multirow[t]{2}{*}{ Tryptophan } & 1 & 1 & 1 & $\underline{(1)}$ \\
\hline & 65 & 65 & 67 & 65 \\
\hline Carbohydrates & + & + & + & + \\
\hline Molecular weight & $\sim 11.500$ & $\sim 11500$ & $\sim 12000$ & $\sim 11500$ \\
\hline
\end{tabular}

${ }^{a}$ H. Tschesche, S. Kupfer, O. Lengel R. Klauser, M. Meier, and H. Fritz, Proleinase Inhibilors, Proc. Int. Res. Conf. 2nd (Bayer Symp. V), Grosse Ledder 1973, p. 156.

II to IV represent seminal inhibitors of about $95 \%$ purity with high specific activities depending on the respective carbohydrate content.

Step 5. Rechromatography on SE-Sephadex. The main fraction II from step 4 is rechromatographed on a column, $1.5 \times 100 \mathrm{~cm}$, of SE-Sephadex C-25. The resin is pretreated as in step 4 and equilibrated with $0.05 M$ ammonium acetate, $\mathrm{pH}$ 6.6. The inhibitor is dissolved in 2-3 ml of $0.05 M$ ammonium acetate, $\mathrm{pH} \mathrm{6.0,} \mathrm{and} \mathrm{applied} \mathrm{to} \mathrm{the} \mathrm{column,}$ which is eluted at room temperature with the equilibrium buffer. The flow rate is $10 \mathrm{ml} / \mathrm{hr}$, and $2-\mathrm{ml}$ fractions are collected. The activity appears in one or two broad pcaks II-1, II-2 or III-1, III-2 (see below), respectively. The fractions pooled from each peak are concentrated by rotary evaporation, desalted by gel filtration on Bio-Gel P-2 in 0.1 $M$ acetic acid, and lyophilized. 
The fractions II-1, and II-2, contain isoinhibitor A. The peaks are not homogencous as revealed by cellulose acetate electrophoresis, but represent multiple chromatographic forms identical in amino acid composition but different in carbohydrate composition (see Table II). If the amino acid analysis is not satisfactory, rechromatography should be repeated. The specific activity of this preparation of isoinhibitor $\mathrm{A}$ is $2.4 \mathrm{IU} / \mathrm{mg}$, depending on the amount of carbohydrates preserved. Fraction III from step 4 is rechromatographed under the same conditions, but repeated rechromatography may be necessary to obtain material with constant amino acid composition representing one of the isoinhibitors $\mathrm{A}, \mathrm{A}_{1}$, or $\mathrm{B}$. The specific activity is higher than that of peak II preparations and varies between 2.8 and $3.1 \mathrm{IU} / \mathrm{mg}$, depending on the amount of carbohydrates present.

\section{Purification of Inhibitors from Spermatozoa}

Step 2. Acidic Extraction. ${ }^{18}$ The frozen sperm pellet (from step 1) is thawed at room temperature and suspended in twice its volume of cold (4) $2 \%(\mathrm{v} / \mathrm{v})$ acetic acid adjusted to $\mathrm{pH} 2.0$ with $2 \mathrm{~N} \mathrm{HCl}$. The suspension is gently stirred for $5 \mathrm{~min}$ and then centrifuged at $1000 \mathrm{~g}$ for 5 min at $4^{\circ}$. The extraction is repeated five times. The extracts are combined, centrifuged at $17,000 \mathrm{~g}$ for $100 \mathrm{~min}$, and concentrated to one-tenth the original volume by ultrafiltration, using Amicôn UM-2 membranes at $4^{\circ}$. Alternatively, lyophilization of the acidic sperm extract is also possible.

Step 3. Separation of Acrosin and Inhibitors. ${ }^{18}$ The acidic sperm extract is subjected to gel filtration. A column, $5 \times 130 \mathrm{~cm}$, of Sephadex G-75 is equilibrated with $2 \%(\mathrm{v} / \mathrm{v})$ acetic acid previously adjusted to $\mathrm{pH} 2.0$ by addition of $2 \mathrm{~N} \mathrm{HCl}$. The column is suitable for handling 15$20 \mathrm{ml}$ of the concentrated solution (or $170 \mathrm{mg}$ of lyophilized extract) and is developed at a flow rate of $30 \mathrm{ml} / \mathrm{hr}$ with $7.5-\mathrm{ml}$ fractions per tube. Acrosin is completely separated (first peak, tubes 60 to 80 ) from the inhibitory activity contained in a single peak. The inhibitor fractions are combined, concentrated by rotary evaporation, and lyophilized. The inhibitor is eluted from the column in the molecular weight range of about 6000 .

Step 4. Gel Filtration at $p H$ 7.8. The preparation obtained in step 3 contains two inhibitor fractions distinguishable by their solubility in neutral and acidic media. One inhibitor fraction can be dissolved by extraction of the preparation from step 3 with $0.4 M \mathrm{NaCl}, 0.1 M$ triethanolamine- $\mathrm{HCl}, \mathrm{pH}$ 7.6. This extract is passed through a Sephadex G-75 column, $1.6 \times 220 \mathrm{~cm}$, equilibrated with the same buffer. The in- 
hibitory activity is cluted in a symmetrical peak; the pooled fractions are concentrated and desalted by ultrafiltration and lyophilized. This material is processed further in step 5 . The other inhibitor fraction of the material from step 3 is soluble only in acidic solutions (below $\mathrm{pH} 4$ ). It is inhibitory-active against trypsin and acrosin; any further churacterization has not yet been done.

Step 5. Chromatography on SE-Sephadex..$^{5}$ In principle the same conditions for ion-exchange chromatography can be used as described for' the seminal plasma inhibitors (see Scction I, step 4). A column, $1.5 \times$ $100 \mathrm{~cm}$, of SE-Sephadex C-25 preconditioned as described above (see Section I, step 4) is equilibrated with $0.015 M$ ammonium acetate, $\mathrm{pH}$ 6.8 , and developed with an ammonium acetate gradient at a rate of 7 $\mathrm{ml} / \mathrm{hr}$. Fractions of $1 \mathrm{ml}$ per tube are collected. After tube 20, a gradient is applied to the column by mixing $0.1 M$ to $100 \mathrm{ml}$ of $0.015 M$ buffer; after tube 150, $0.3 M$ buffer is mixed with $100 \mathrm{ml}$ of $0.1 M$ buffer. The absorbance at $280 \mathrm{~nm}$ and the inhibitory activity against trypsin is monitored. The main inhibitor fractions, tubes 200 to 225, are combined, concentrated, desalted on Bio-Gel P-2 in $0.1 M$ acetic acid, and lyophilized.

Step 6. Rechromatography on SE-Sephadex. The inhibitor is subjected to rechromatography under slightly morlificd conditions. A smaller column, $0.9 \times 60 \mathrm{~cm}$, of SE-Sephadex C-25 cquilibrated with $0.05 \mathrm{M}$ ammonium acetate, $\mathrm{pH}^{\mathrm{m}} 6.8$, is eluted with an ammonium actate gradient formed from $0.05 M$ to $0.3 M$ buffer. Inhibitor of $95 \%$ purity is collected from the main fraction, its amino acid composition is presented in Table I.

\section{Properties}

Stability. The isoinhibitors $\mathrm{A}, \mathrm{A}_{1}$, or $\mathrm{B}$ are stable in acid and neutral solution. There is no loss of activity when the seminal plasma inhibitors are heated to $100^{\circ}$ in neutral buffers or to $75^{\circ}$ in $3 \%$ perchloric acid or if heated for $23 \mathrm{hr}$ at $40^{\circ}$ in the dry state. The inhibitors are digested by thermolysin at $25^{\circ} .8$

Physical Properties. The boar seminal plasma inhibitor is a glycoprotcin. ${ }^{3,5,8,11}$ It exists in at least two forms with respect to its protein part. Isoinhilbitor $A$ and $A_{1}$ contain 65 amino acid residues; isoinhibitor B contains two additional amino acid residues." Minimal molecular weights of 7599 and 7856 are calculated on the basis of the amino acid composition for the protein portions of the inhibitor molecules. Including the carbohydrate residues (Table II), however, molecular weights from 11,000 up to 12,000 are calculated for some of the multiple chromato- 
TABLE II

Carbohydratp: Composition of Boar Seminal Plasma Isoinhibitors ${ }^{n}$

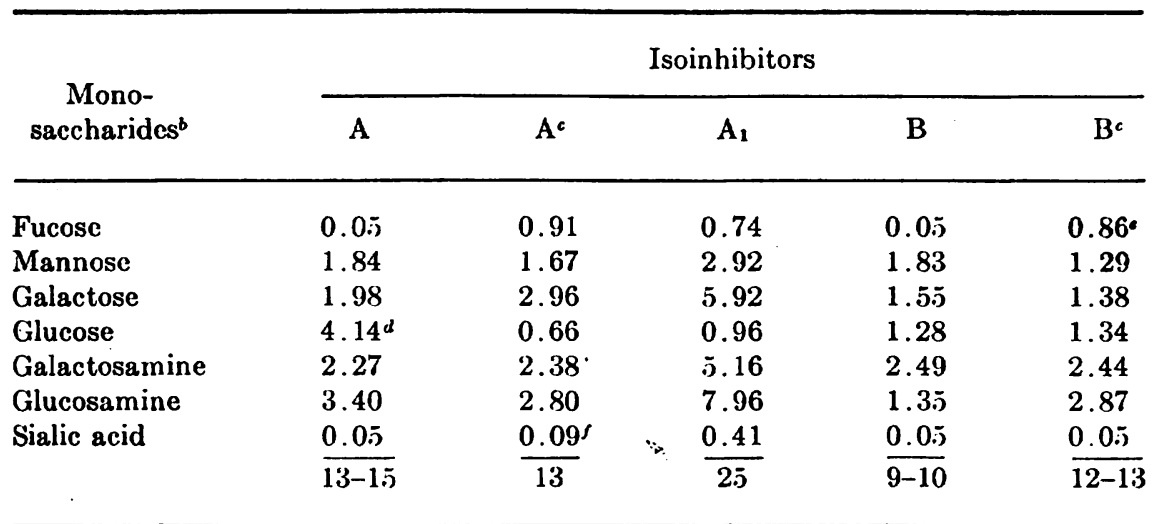

a Calculated for total MW 11,000.

b Determined after HCl-methanolysis, acetylation, and silylation by gas chromatography.

.c Other peak from SE-Sephadex separation of isoinhibitors.

¿ Sample dialyzed for $60 \mathrm{hr}$ against 25 liters of distilled water prior to carbohydrate determination.

- Determined by cysteine- $\mathrm{H}_{2} \mathrm{SO}_{4}$ method according to Dische and Shettles.

$\checkmark$ Determined by resorcinol method according to Svennerholm.

graphic forms. ${ }^{5,11}$ The molar UV absorbance of isoinhibitor $A_{1}$ of MW 12,000 as calculated from the amino acid and carbohydrate composition is found at $\mathrm{pH} 6.0$ to $\epsilon_{278 \mathrm{~nm}}^{1 \mathrm{~cm}}=11,700 .^{8}$ From titrations of bovine trypsin ${ }^{3}$ and boar acrosin' and the specific inhibitor activity, a molecular weight of approximately 13,000 is calculated for the high-molecularweight form.

The inhibitors isolated by the procedure described in this article differ strongly in their carbohydrate content. This might explain the differences in the molecular weights of the boar seminal plasma inhibitors reported earlier (about 13,500 in acidic solutions ${ }^{3,6}$ and 12,000 in neutral solution ${ }^{3}$ ). The occurrence of forms with lower molecular weights (70005800 and even 1600$)^{4,6,7,20}$ might be due to a more extensive removal of carbohydrate residues and perhaps also $\mathrm{C}$ - and $\mathrm{N}$-terminal amino acid residues either by the hydrolytic effect of enzymes or acid-induced cleavages.

Purity. Isoinhibitor $\mathrm{A}, \mathrm{A}_{1}$, or $\mathrm{B}$ are microheterogeneous in their carbohydrates and therefore are resolved in cellulose acetate electrophoresis at $\mathrm{pH} 7.8$ into several bands having the same amino acid compositions. ${ }^{5}$ At least one to two dozen multiple chromatographic forms could be dis- 
tinguished in the crude preparation from step 3 by ion equilibrium chromatography on SE-Scphadex C-25."

Specificity. Isoinhibitors $A, A_{1}$, or $B$ and all unidentified intermediate chromatographic forms have equal effects on the tryptic digestion of casein, gelatin, BAEE, and BAPA. They inhibit acrosin of boari, ${ }^{i-7,9} \mathrm{mIl}$ man, ${ }^{10}$ trypsins of $\operatorname{cow}^{3,4,5-i}$ and pig, ${ }^{3,5}$ and human plasmin, ${ }^{28} \alpha-C l y y m o-$ trypsin is inhibited to some extent by excess of any of the inhibitors. Human thrombin, human neutral leukocytic proteinases and porcine pan-1 creatic kallikrein are not inhibited, though seminal plasma contains very small amounts of inhibitors for the latter enzyme. ${ }^{7}$

Kinetic Properties. The inhibition of acrosin, trypsin, and plasmin by inhibitors from seminal plasma and spermatozoa is instantaneous and stoichiometric. . $^{3,5-7,0-11}$ The inhibition constants derived from titrations (with BAPA as substrate and against NPGB-titrated enzymes) are as follows: for boar acrosin, $K_{\mathrm{i}}=1.4 \mathrm{n} M$; for bovine $\beta$-trypsin, $K_{\mathrm{i}}=3.2$ $\mathrm{n} M$, and for porcine plasmin, $K_{\mathrm{i}}=0.12 \mu M .^{5}$

When the virgin inhibitor reacts with catalytic amounts of boar acrosin at $\mathrm{pH} 3.75$, the reactive site peptide bond $\mathrm{Arg}_{10}-\mathrm{Gln}_{20}$ is hydrolyzed, and modified inhibitor is formed. ${ }^{5}$ The modified inhibitor retains its activity against acrosin, trypsin, and plasmin. A thermodynamic equilibrium between $76 \mp 2 \%$ virgin and $24 \mp 2 \%$ modified inhibitor is attained, giving a $\mathrm{K}_{\text {hyd }}$ of $0.33 .^{5,8,11}$

The inhibition of trypsin is of a temporary mode. ${ }^{5,11,21}$ The inhibitor even in $0.5 M$ excess over trypsin is completely inactivated after $20 \mathrm{hr}$ at $\mathrm{pH} 7.8\left(0.02 \mathrm{M}\right.$ in $\left.\mathrm{CaCl}_{2}\right)$ and $25^{\circ} .^{11}$ The inhibition of boar acrosin is pscudopermanent; if acrosin is incubated with a $0.7 M$ excess of inhibitor at $\mathrm{pH} 7.8\left(0.02 \mathrm{M}\right.$ in $\left.\mathrm{CaCl}_{2}\right)$ at $22^{\circ}$, the inhibitor is almost completely inactivated after 20 days. ${ }^{11,21}$ At $\mathrm{pH} 3.75$ and $0.5 M$ excess, the inhibitor is inactivated after 4.5 days at $22^{\circ} .^{21}$

Amino Acid Composition. The compositions of the isoinhibitors A, $A_{1}$, and $B$ are shown in Table $I$. All inhibitors have identical compositions except for the lysine and arginine residues. All contain one residue each of methionine and tryptophan.

Carbohydrate Composition. The carbohydrate composition of several chromatographic forms obtained after Sephadex G-75 gel filtration followed by ion equilibrium chromatography on SE-Sephadex C-25 using the system described in step 4 and 5 are given in Table II. The different compositions reveal a microheterogeneity. All inhibitors contain the monosaccharide units galactose, glucose, mannose, galactosamine, and

${ }^{22}$ W. Kalckreuth, Dissertion (M.D. thesis), Medical Faculty, University of Munich, 1972. 


\section{Bonsuseminal}

Guinea plg seminal

Porcine pancreatic I

Bovine pancreatic
Thr Arg Lys Gin Pro Asn Cys - - - - - - Asn Val Tyr Arg Ser His Leu Phe Ala Pro Ser Lys Val Asx Ser Cys - Arg - Pro Asx Ser Asx - Arg Tyr Val Glx Thr Ser Pro Gln Arg Glu Ala Thr Cys - - - - - Thr Ser Glu Val Ser - Gly Asn Ile Leu Gly Arg Glu Ala Lys Cys - - - - - Thr Asn Glu Val Asn - Gly

Boar seminal $\quad$ - . - - Phe Phe Cys Thr Arg Gln Met Asp Pro ne Cys Gly Thr Asn Gly Lys Ser Tyr Ala Asn Pro Cys Guinea pig seminal Arg - - Tyr Met Cys Thr Lys (Glx Leu Asx Pro Val [Cys, Gly, Thr, Asx, Gly, His, Thr] Tyr)

Porcine pancreatic I His Leu - - - Cys Pro Lys lle Tyr Asn Pro Val Cys Gly Thr Asp Gly Ile Thr Tyr Ser Asn Glu Cys Bovine pancreatic - - - - - Cys Pro Arg lle Tyr Asn Pro Val Cys Gly Thr Asp Gly Val Thr Tyr Ser Asn Glu Cys

Boar seminal He Phe Cys Ser Glu Lys Gly Leu Arg Asn Gin Lys Phe Asp Phe Gly His Trp Gly His Cys Arg Glu Tyr Thr Ser Ala Arg Ser Guinea pig seminal (Phe Thr Phe Ser His Tyr Gly Arg)

Porcine pancreatic I Val Leu Cys Ser Glu Asn Lys Lys Arg Gin Thr Pro Val Leu Ile Gln Lys Ser Gly Pro Cys Bovine pancreatic Leu Leu Cys Met Glu Asn Lys Glu Arg Gln Thr Pro Val Leu Ile Gln Lys Ser Gly Pro Cys

Fig. 2. Alignment of the homologous amino acid sequences of the boar seminal plasma acrosin inhibitor (top line) [H. Tschesche, S. Kupfer, R. Klauser, E. Fink, and H. Fritz, in "Protides of the Biological Fluids, 23rd Colloquium" (H. Peeters, eds.), p. 225, Pergamon, Oxford and New York, 1976.] and the partial sequence of the guinea pig seminal vesicles trypsin-plasmin inhibitor (a) with the sequences of the porcine (b, c, d) and bovine (e) pancreatic secretory trypsin inhibitors. For further structurally homologous inhibitors, see H. Tschesche, S. Kupfer, R. Klauser, E. Fink, and H. Fritz, in "Protides of the Biological Fluids, 23rd Colloquium" (H. Peeters, ed.), p. 225, Pergamon, Oxford and New York, 1976; this volume [70], [73], and [76]. I. Kato, J. Schrode, K. A. Wilson, and M. Laskowski, J., in "Protides of the Biological Fluids, 23rd Colloquium" (H. Peeters, ed.), Pergamon, Oxford and New York, 1976; L. J. Greene and D. C. Bartelt, in "Protides of the Biological Fluids, 23rd Colloquium" (H. Peeters, ed.), Pergamon, Oxford and New York, 1976; (a) E. Fink, Dissertation, Ph.D. Thesis, Faculty of Natural Science, University of Munich, 1970; and unpublished results. (b) H. Tschesche, E. Wachter, S. Kupfer, and K. Niedermeier, Hoppe-Seyler's Z. Physiol. Chem. 350, 1247 (1969). (c) H. Tschesche and E. Wachter, Eur. J. Biochem. 16, 187 (1970). (d) D. C. Bartelt and L. J. Greene, J. Biol. Chem. 246, 2218 (1971). (e) L. J. Greene and D. C. Bartelt, J. Biol. Chem. 244, 2646 (1969). 


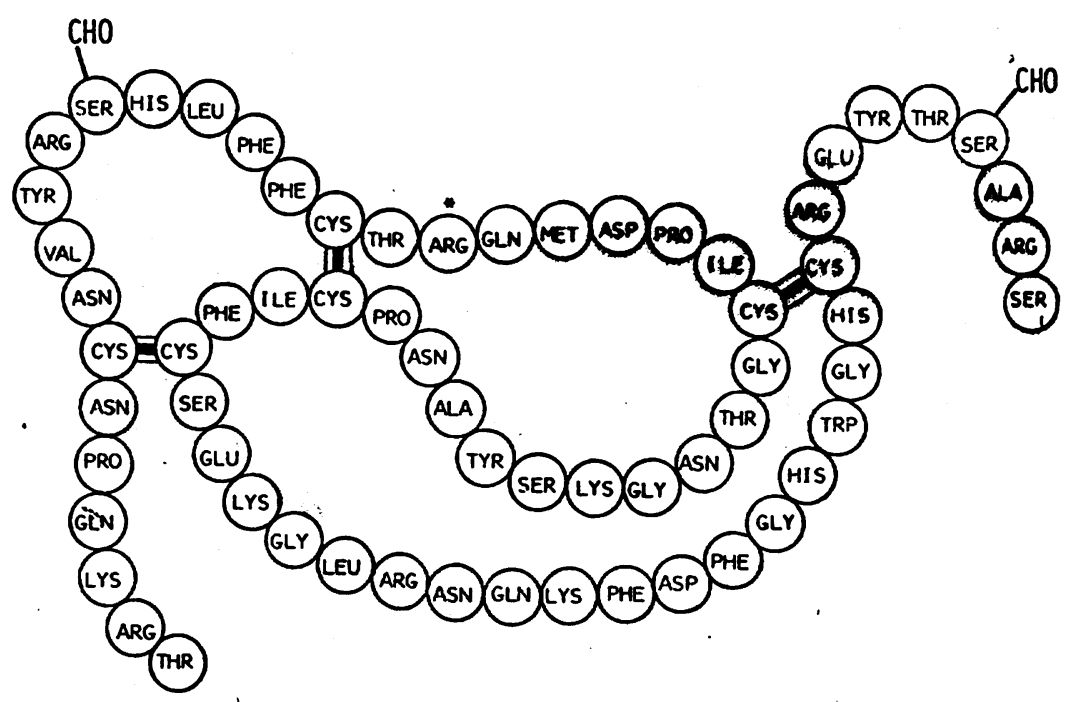

Fia. 3. Schematic diagram of the covalent structure of the boar seminal plasma acrosin inhibitor $A_{t}$ [H. Tschesche, S. Kupfer, R. Klauser, E. Fink, and H. Fritz, in "Protides of the Biological Fluids, 23rd Colloquium" (H. Peeters, ed.), p. 225, Pergamon, Oxford and New York, 1976; H. Tschesche and S. Kupfer, unpublished results, 1975.

glucosamine; some in addition contain fucose and sialic acid. The sialic acid content is due to $\mathrm{N}$-acetylneuraminic acid and glycolylneuraminic acid. ${ }^{23}$ The carbohydrates are attached by $O$-glycosidic bonds to $\operatorname{Ser}_{12}$ and $\operatorname{Ser}_{63}{ }^{8,11}$ forming two carbohydrate moieties.

Covalent Structure. The amino acid sequence of inhibitor $A_{1}$ is given in Fig. 2 and compared to those of other members of this family of proteinase inhibitors (Kazal type) thus far elucidated.11 The positions of the disulfide bridges ${ }^{8}$ and the probable attachment sites of the carbohydrate moieties are shown in Fig. 3.

\section{Biological Aspects ${ }^{7}$}

Antibodies against BSTI-I, BSTI-II (see Section I, Step 3a) and the mixture of both inhibitors have been raised in rabbits. BSTI-I-directed antibodies cross-react with BSTI-II inhibitor and BSTI-II-directed antibodies with BSTI-I inhibitor. Using the indirect immunofluorescence method, the inhibitors have been localized in the epithelial cells of the tail of the epididymis, of the ductus deferens, of the seminal vesicles, of the prostate (smaller cell aggregates only), and of the urethra by intense

${ }^{2}$ R. Klauser and H. Tschesche, unpublished results, 1975. 